\title{
Análise da crise do Subprime e os derivativos de crédito nos Estados Unidos da América
}

Analysis of the Subprime crisis and credit derivatives in the United States of America

Análisis de la crisis del Subprime y los derivados de crédito en los mercados Estados Unidos de América

Analyse de la crise des subprimes et des dérivés de crédit dans le États-Unis d'Amérique

Marcos Ruppelt, André Brum Missaggia, Bruno Miranda dos Santos e Franco da Silveira

\section{(2) OpenEdition}

\section{Journals}

Edição electrónica

URL: http://journals.openedition.org/espacoeconomia/4342

DOI: $10.4000 /$ espacoeconomia.4342

ISSN: 2317-7837

Editora

Núcleo de Pesquisa Espaço \& Economia

Refêrencia eletrónica

Marcos Ruppelt, André Brum Missaggia, Bruno Miranda dos Santos e Franco da Silveira, « Análise da crise do Subprime e os derivativos de crédito nos Estados Unidos da América ", Espaço e Economia [Online], 13 | 2018, posto online no dia 03 dezembro 2018, consultado o 19 abril 2019. URL : http:// journals.openedition.org/espacoeconomia/4342 ; DOI : 10.4000/espacoeconomia.4342

Este documento foi criado de forma automática no dia 19 Abril 2019.

(c) NUPEE 


\section{Análise da crise do Subprime e os derivativos de crédito nos Estados Unidos da América}

Analysis of the Subprime crisis and credit derivatives in the United States of

America

Análisis de la crisis del Subprime y los derivados de crédito en los mercados

Estados Unidos de América

Analyse de la crise des subprimes et des dérivés de crédit dans le États-Unis

d'Amérique

Marcos Ruppelt, André Brum Missaggia, Bruno Miranda dos Santos e

Franco da Silveira

\section{Introdução}

1 A crise de 2008, também conhecida como crise do subprime, foi um dos maiores marcos na historia do mercado financeiro mundial. Mais de oito milhões de pessoas perderam seus empregos e suas casas, isso apenas nos Estados Unidos. Os impactos causados por essa crise são sentidos até hoje por instituições bancárias, regulatórias e governamentais (NAPPI, 2017). A derrocada do mercado imobiliário americano foi um dos pontos centrais da crise que permitiu perdas gigantescas de recursos financeiros em títulos lastreados em dívidas e ativos deste mercado (FREITAS, SILVA e FIGUEIREDO, 2016). Mas o que esta pesquisa buscará estudar não são, apenas, os produtos que perderam valor durante a crise, mas, também, aqueles que se tornaram ferramentas de ganho, de geração de valor.

Os derivativos de crédito possibilitaram ganhos significativos para investidores e fundos que acompanharam, de maneira analítica e cautelosa, os movimentos do mercado financeiro e imobiliário americano na primeira década do século XXI (RODRIGUES, 2015). Os derivativos de crédito são mecanismos utilizados pelos bancos para transferir o risco de determinada operação. Os riscos inerentes do mercado financeiro, por exemplo, 
crédito, preço de ativos, são minimizados através de contratos de derivativos. Esses contratos podem ser negociados na bolsa de valores ou de forma bilateral, diretamente entre as partes envolvidas (BESSANA, BARBEDO, ARAÚJO e 2015; FIGUEIREDO, 2016). Esses instrumentos financeiros serviram de base para criações de seguros contra calote de títulos hipotecários, proteções, entre outras operações. A importância deste estudo reside no fato de que os acontecimentos registrados na crise do subprime impactaram a vida de milhões de pessoas, como por exemplo, taxa de câmbio, comércio internacional além de impactar negativamente os mercados emergentes (FANG et al., 2013; KARTIO et al., 2017). O subprime surgiu pois o setor bancário americano passou a agregar créditos e outros produtos para pessoas que tinham condições de realizar o pagamento e para as que não tinham sequer renda comprovada. (KRUGMAN, 2009; SHIRAI, 2009, FANG et al. 2013; RICCI, 2017).

Entender como um desastre econômico aconteceu e quais os instrumentos financeiros envolvidos nesse evento é fundamental para pesquisadores e profissionais de mercado. Mesmo quase uma década após a quebra de gigantes como Lehman Brothers e Bear Stearns, este tema ainda paira sobre a sociedade mundial recheado de dúvidas e incertezas. $O$ fato de que o governo, agentes regulatórios, gigantes do setor bancário e pequenas empresas estiveram envolvidos nas perdas massivas desta crise tornam mais válido ainda o estudo, visto o impacto que as perdas tiveram na vida da população mundial. Mesmo que pequena, a contribuição aqui esperada é direcionar uma luz para um tema, por vezes esquecido, e que precisa ser lembrado, sempre que possível, para que o mercado financeiro não cometa os mesmos erros daqui algumas décadas.

Diante disso, o problema de pesquisa deste artigo consiste em responder a seguinte questão: quais são os fundamentos dos instrumentos financeiros que possibilitaram perdas e ganhos com a crise do subprime de uma maneira nunca antes vista no mercado financeiro mundial? Desta forma, para que seja possível atuar em cima do problema de pesquisa citado, este estudo terá por objetivo geral estudar os instrumentos financeiros que permitiram grandes perdas e consideráveis ganhos com a crise do subprime. Para atingir o objetivo geral definido, foram delineados três caminhos para entender o contexto geral do que foi proposto, dessa forma, primeiramente será necessário analisar as estruturas e produtos financeiros que exerceram influência na crise de 2008, após foi analisado de que forma os derivativos de crédito foram utilizados para geral recursos durante a crise e, por fim, a identificação de possibilidades distintas de utilização desses instrumentos no mercado financeiro.

\section{Contextualização da Crise Financeira nos Estados Unidos da América}

Em 2001, Alan Greenspan, o presidente do Federal Reserve System, o Banco Central dos Estados Unidos, declarou que o setor imobiliário seria o setor da vez na América. Depois dos negócios virtuais e das empresas de tecnologia ter um período glorioso ao final do século XX, resultando na famosa "bolha da internet", uma superestimação de preços das empresas pelo mercado, agora seriam os imóveis o foco dos recursos e da atenção governamental. Para isso, segundo Freitas e Cintra (2008), adotou-se uma política de juros baixíssimos e redução de despesas financeiras, fazendo com que os intermediários financeiros trouxessem uma clientela cada vez maior a investir em imóveis e títulos hipotecários. 
Os Títulos Hipotecários (MBS) foram peça central no mercado imobiliário americano durante muito tempo. Não apenas por representarem uma ferramenta eficiente e segura para investimento, mas por terem atrelado ao seu lastro um dos pilares econômicos americanos: a hipoteca.

7 Segundo Cintra e Cagnin (2007), se olharmos o mercado americano desde a década de 80 ao ano anterior à crise de 2008, fica evidente que investidores institucionais, grandes corporações, e, até mesmo, o crédito e a poupança das famílias, sempre esteve muito direcionado para o mercado de capitais. Entretanto, alguns valores chamavam a atenção para oportunidades futuras. "Por sua vez, a participação dos bônus corporativos praticamente duplicou, aumentando de $10,7 \%$ para $22,1 \%$ no mesmo período. A participação das hipotecas flutuou em torno de $24 \%$ a $30 \%$ durante todo o período" (CINTRA e CAGNIN, 2007, p.7). A Figura 1 apresenta o estoque de endividamento privado americano ao longo de 30 anos.

Figura 1 - Estoque de endividamento privado, por instrumento - US\$ trilhões

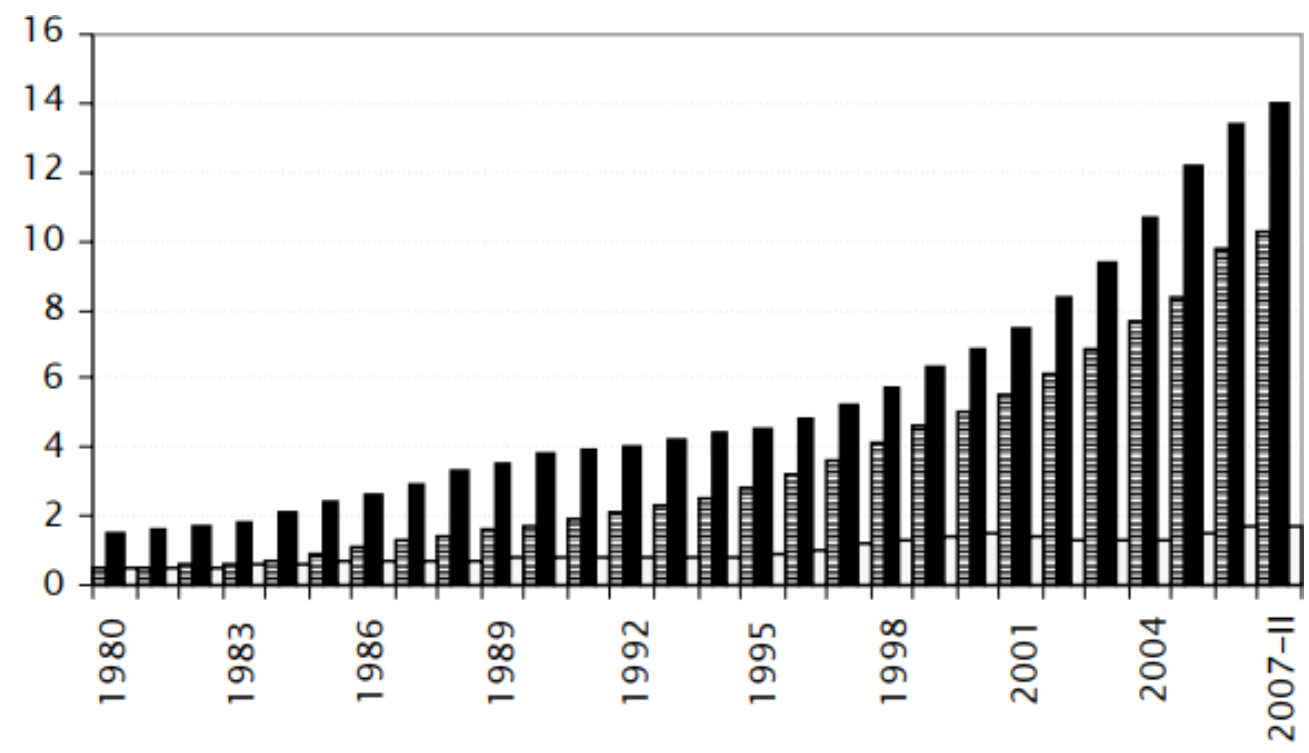

Bônus corporativos e estrangeiros

Hipoteca

Empréstimos bancários

Fonte: Adaptado de (CINTRA e CAGNIN, 2007, p.7).

Conforme a Figura 1, diversas transformações estruturais ocorridas no setor imobiliário americano, anteriores a liberação de crédito proposta por Alan Greenspan no começo do século XXI, explicam a evolução da participação das hipotecas no endividamento total do setor privado. Segundo Cintra e Cagnin (2007), diversas medidas tomadas pelo governo norte- americano foi no sentido de atenuar os impactos observados em diversas instituições com desequilíbrios patrimoniais, o que acabou por promover o desenvolvimento de um mercado secundário securitizado de hipotecas. A criação desse mercado levou a oficialização do termo Mortgage Backed Securities (MBS) como o título hipotecário vanilla (padrão). Isso acabou estreitando os vínculos entre o mercado de capitais e o mercado de hipotecas.

9 Michael Lewis (2011), o famoso escritor norte-americano e ex funcionário do Salomon Brothers, relata que foi um ex-colega de sua empresa, Lewis Ranieri, um operador de 
títulos, que difundiu o conceito e o padrão de comercialização dos MBS entre os operadores do mercado americano na década de 70. Lewis (2011) afirma que um dos grandes desafios para absorção e difusão do MBS no mercado foi o fato de que não se caracterizava como um único empréstimo gigantesco por um prazo fixo preestabelecido, e, sim, como uma participação nos fluxos de caixa de um grupo enorme de hipotecas residenciais individuais. Isso mostra que os títulos hipotecários eram significativamente diferente dos títulos de dívida governamental e corporativa. "Esses fluxos de caixa sempre foram problemáticos, pois os tomadores dos empréstimos tinham o direito de saldá-los a qualquer momento que quisessem" (LEWIS, 2011, p. 26). Esse fato justificou por um bom tempo o motivo pelo qual os investidores em títulos haviam evitado investir em empréstimos baseados em hipotecas residenciais. Era claro para os operadores que o investidor em empréstimos imobiliários não sabia o quanto seu investimento duraria, sabia apenas que não receberia o dinheiro de volta quando menos esperasse.

Lewis (2011) afirma que para limitar essa incerteza, as pessoas com as quais eu trabalhava no Salomon Brothers, que criaram o mercado de títulos hipotecários, chegaram a uma solução inteligente. Tomaram conjuntos gigantescos de empréstimos imobiliários e dividiram os pagamentos efetuados pelos proprietários dos imóveis em partes chamadas tranches. 0 mesmo autor faz uma análise simples para entender a proporção do problema que estava surgindo, onde ele basicamente afirma que o comprador da primeira tranche era como o proprietário de um imóvel no piso térreo que seria atingido por uma enchente. $\mathrm{O}$ comprador da segunda tranche estaria no segundo andar de um arranha-céu e assim por diante. Essa analogia serve para entender que o primeiro comprador seria quem receberia a primeira onda de pagamentos antecipados de hipotecas. Em troca, sua taxa de juros seria maior. 0 mesmo aconteceria com o segundo comprador, na segunda onda de pagamentos antecipados recebendo, em troca, uma segunda maior taxa de juros. Por fim, o investidor no último andar do prédio recebia a menor taxa de juros, mas tinha a maior garantia de que seu investimento não terminaria antes que desejasse. $O$ autor resume este ponto da seguinte forma: "O grande temor do investidor em títulos hipotecários da década de 1980 não era a falta de pagamento, mas ser pago rápido demais" (LEWIS, 2011, p. 28).

11 Um dos principais pontos de mudança relevantes nesse mercado foi quando os títulos hipotecários passaram a ganhar novos usos como, por exemplo, a realização de empréstimos que não se encaixavam nas garantias governamentais. o objetivo era simples: estender o crédito a proprietários de imóveis com cada vez menos capacidade de pagar esses créditos, não para que tivessem condições de comprar uma casa, mas para que pudessem sacar o valor líquido da residência que já possuíam. De acordo com Lewis (2011), "os títulos hipotecários criados a partir de empréstimos imobiliários subprime expandiram a lógica inventada para lidar com o problema do reembolso, a fim de resolver o problema da falta de pagamento". Voltando ao exemplo anterior, o que se teria agora é o investidor da primeira tranche sendo exposto aos prejuízos reais e não aos pagamentos antecipados. Dessa forma, o prejuízo só atingiria o investidor da segunda tranche, quando os primeiros prejuízos tivessem arruinado inteiramente o primeiro investidor.

12 A transformação das hipotecas residenciais em títulos e, posteriormente, a evolução da exploração desse passivo como algo que pudesse ser transformado em novas operações para outras pessoas foi visto inicialmente como algo positivo. "Essa nova eficiência nos mercados de capitais permitiria que americanos de classe média baixa pagassem taxas de juros cada vez menores sobre suas dívidas" (LEWIS, 2011, p. 30). o que não havia sido 
mapeado na época era que, menos de 30 anos depois, a grande maioria dos títulos hipotecários estariam recheados de hipotecas de alto risco (subprime), com classificações de risco enganosas e taxas variáveis exorbitantes. Na visão de Randolph e McKay (2015), talvez o fato dos bancos terem ganhado bilhões de dólares cobrando honorários de $2 \%$ para cada título hipotecário vendido possa sim ter contribuído para esse controle questionável do mercado, mas fato é que nenhum país do mundo possui tantas casas ou tanta gente bem empregada com capacidade para pagar por elas. As hipotecas ficariam escassas mais cedo ou mais tarde, então o processo de adesão dos MBS as hipotecas de maior risco era um caminho natural para um mercado muito rentável e em constante crescimento.

\section{Crise do Subprime}

13 O movimento governamental de incentivo ao investimento no mercado imobiliário atrelado a extrema disseminação dos MBS, contemplados, em sua maioria, por hipotecas de alto risco foi o ponto de virada crucial desta historia. Lewis (2011) conta que Michael Burry, criador do hedge fund Scion Capital, deixa muito claro dentro de seus estudos e pesquisas publicados na internet que, já em 2004, era possível identificar a decaída no padrão dos empréstimos pelos agentes financeiros americanos. "Os padrões não só tinham caído, mas alcançado seu pior nível. o fundo do poço tinha até nome: hipoteca subprime com taxa ajustável e amortização negativa com pagamento apenas de juros" (LEWIS, 2011, p. 51). Basicamente, o autor se refere a um tipo de negócio em que o comprador do imóvel residencial tinha a opção de não pagar e transferir os juros devidos a instituição financeira para um saldo principal maior. Essas operações atraíam, basicamente, pessoas sem renda. "O que Michael Burry não conseguia entender era porque uma pessoa que emprestou dinheiro desejaria estender tal empréstimo" (LEWIS, 2011, p. 51). A resposta para esse questionamento de Burry não tinha nenhum mistério. Os tomadores de empréstimos estavam apenas aproveitando as estruturas montadas pelos credores, que, por anos, não demonstraram nenhum comedimento e atenção ao risco dentro de suas operações. Tudo isso, supervisionado e incentivado pelo governo e agências financeiras.

Charles Randolph (2015) afirma na adaptação do livro de Lewis que Michael Burry tinha certeza que o aumento da complexidade e dos índices de fraude nas operações eram indicadores claros para crises envolvendo o mercado de hipotecas. Na década de 30, mais da metade das dívidas hipotecárias americanas não eram pagas. Com a "bolha da internet", na virada do século, movimentos semelhantes aconteceram. E lá por 2004, apenas olhando os números, Burry observou índices de fraude vistos anteriormente apenas durante a Grande Depressão.

Michael Burry foi o primeiro investidor do mercado acionário a admitir publicamente receio de que o mercado escondia nos anos pré-crise. O principal deles era o famoso argumento de que não existia mercado mais sólido do que o imobiliário. Apenas olhando indicadores, Burry chegou à conclusão de que as casas não eram mais bens, eram apenas dívidas, e quase todas não pagas. Indicadores como fraudes hipotecárias quintuplicando, salário médio estável, sem crescimento algum, e preço das casas disparando, fizeram com que não apenas Burry, como diversos outros investidores e players do mercado, começassem a enxergar que operar vendido talvez pudesse ser o caminho mais correto, quando se tratava de títulos hipotecários de alto risco. Essa ideia por mais racional que 
possa soar atualmente, quando discutida nos anos anteriores à crise de 2008, era tratado com ironia e humor pelos agentes financeiros envolvidos nos bilhões de dólares negociados em títulos hipotecários anualmente.

Os empréstimos hipotecários de alto risco e taxa variável (pós-fixadas e determinadas no momento do pagamento da dívida) passaram a ser adquiridos em volumes altíssimos por clientes sem comprovação de renda e com histórico ruim de crédito. Steve Eisman, um dos investidores que ganhou maior fama, após a crise de 2008, por ter investido contra os títulos hipotecários recursos consideráveis da FrontPoint Partners, fundo que ele criou e era gerido sob tutela do Morgan Stanley, compartilhava no trabalho e entre amigos a ideia clara de que muitas pessoas que trabalhavam no mercado financeiro não conseguiam entender de fato o que estavam fazendo. Conforme Lewis (2011, p. 50), trinta bilhões de dólares haviam sido significativos para os empréstimos subprime em meados da década de 1990. Em 2000, foram US\$130 bilhões em empréstimos hipotecários subprime, e US $\$ 55$ bilhões foram reempacotados como títulos hipotecários. Em 2005, US\$625 bilhões em empréstimos hipotecários subprime, US $\$ 507$ bilhões dos quais viraram títulos hipotecários. Ou seja, meio trilhão de dólares em títulos lastreados em hipotecas subprime em um único ano.

Em 2005, no auge dos empréstimos subprime, os Estados Unidos passava por um período de aumento de juros. Ao passo que o governo cortava limitações e restrições de crédito para o mercado imobiliário e os agentes financeiros, o Federal Reserve System (FED) aumentava a taxa de juros para controlar a inflação. Os clientes sem renda tomadores de empréstimos naturalmente passaram a sofrer as primeiras grandes perdas. Segundo Silva e Pinese (2005), esse movimento citado foi um marco, pois os clientes passaram a ter grandes dificuldades no pagamento das prestações e acabaram não conseguindo refinanciar imóveis devido à mudança no cenário do valor dos imóveis. Dessa forma, com o início das desvalorizações, foi possível observar uma inadimplência em massa no mercado americano.

Randolph e McKay (2015) trouxe uma provocação importante dentro desse cenário:o que realmente permitiu que uma crise imobiliária virasse um desastre econômico não foram apenas os movimentos econômicos errados por parte da política econômica americana, nem mesmo a comercialização excessiva de títulos com hipotecas de alto risco, mas, principalmente, o empacotamento das dívidas criadas com o não pagamento das hipotecas para sua posterior recomercialização feita pelos bancos, no que foi disseminado como Collateralized Debt Obligation (CDO), que, nada mais eram, do que títulos lastreados em dívidas.

\section{Derivativos de Crédito}

19 Segundo Bonfim (2007, p. 148), os CDOs são essencialmente "títulos com diferentes níveis de seniority e com pagamentos de principal e taxa de juros suportados pelos fluxos de caixa de um portfólio de instrumentos de dívida como objeto.". Quando os instrumentos de dívida forem empréstimos, a CDO se torna uma CLO (obrigações garantidas por empréstimos), se são bônus, a CDO pode se tornar uma CBO (obrigações garantidas por bônus), e assim por diante. Para facilitar a compreensão, Bonfim (2007) incentiva o uso de exemplos como o seguinte: se pegarmos um emissor de CDO com um portfólio de empréstimos no valor total de, aproximadamente, $\mathrm{R} \$ 100$ milhões, para que ele consiga financiar a compra desse portfólio citado, o emissor venderá obrigações de dívidas a 
investidores, que nada mais são do que notas. 0 que irá garantir o pagamento prometido por essas notas são os fluxos de caixas gerados pelo portfólio de $\mathrm{R} \$ 100$ milhões do emissor. A estrutura desse CDO é apresentada na Figura 2.

Figura 2 - Diagrama de uma CDO simples.

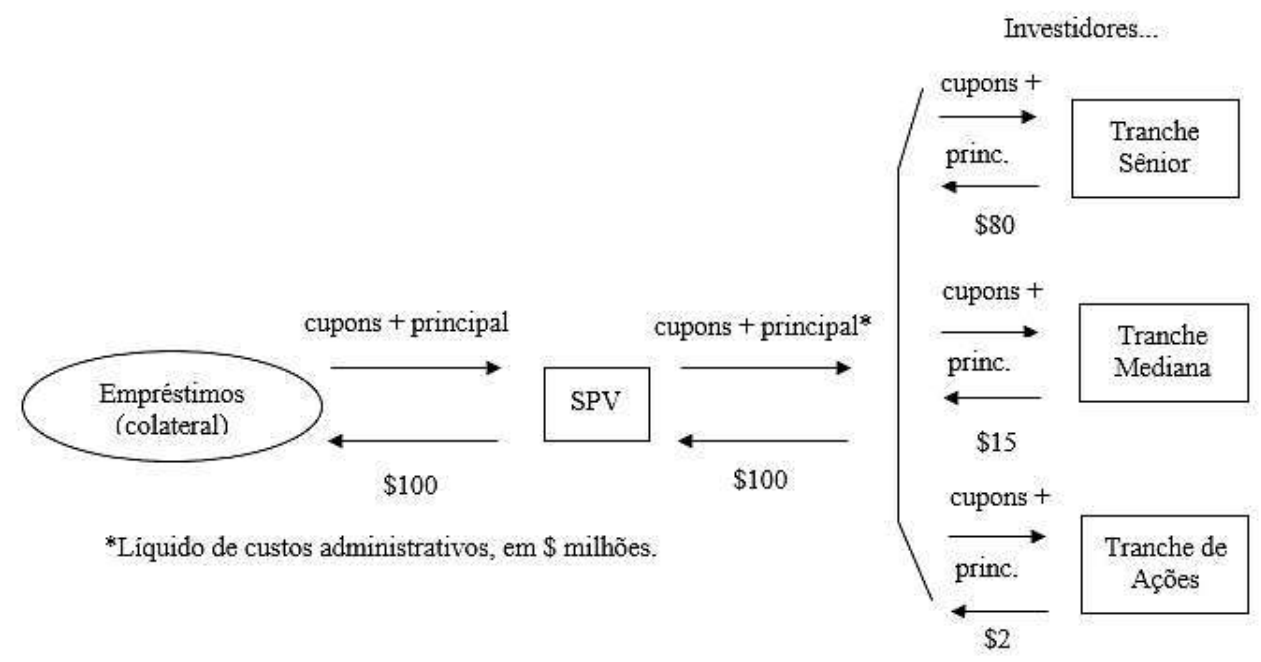

Fonte: (BONFIM, 2007, p. 149). classificações das diferentes tranches desses títulos e obrigações de dívidas eram feitos pelas principais agências de classificação de crédito, como Moody's, Standard and Poor's e Fitch Ratings, as quais, teoricamente, deveriam atuar com independência e parcimônia, cumprindo seu papel como agente no mercado financeiro, mas que, ao longo da crise, se relevaram mais comprometidas com uma classificação que agradasse seus principais clientes do que fossem de acordo com a realidade de queda do mercado imobiliário. para diferentes fins, de acordo com os objetivos finais de seus patrocinadores. "Por exemplo, a partir da perspectiva de um banco comercial, as CDOs tornam possível transferir um grande portfólio de empréstimos do balanço patrimonial do banco por meio de uma simples transação com uma repackaging vehicle" (BONFIM, 2007, p. 151). Essas 
CDOs são chamadas de CDOs sobre balanço patrimonial e, historicamente, refletem o desejo dos bancos de liberar o capital regulatório. Esse tipo de operação, frequente, em especial, nos anos 90, é fundamentado na ideia do banco vender seus ativos para os SPVs, os quais irão os securitizar e, a partir disso, envolver investidores institucionais.

Nos últimos anos, grande parte das emissões de CDOs tem tido relação direta com a demanda dos investidores para alavancar suas exposições ao risco de crédito, e, não tanto, pela necessidade de gerenciar melhor balanços patrimoniais de instituições bancárias. Esse tipo de CDO é conhecido, no mercado, como CDO para arbitragem, aonde as instituições por trás das emissões, irão buscar melhorar seus retornos sobre os ativosobjeto, tornando-se investidores de primeira perda nas estruturas recentemente criadas. "A maioria dessas CDOs para arbitragem é ativamente gerenciada e, assim, os investidores das CDOs estão expostos tanto ao risco de crédito quanto a estratégia comercial particular seguida pelo administrador da CDO" (BONFIM, 2007, p. 151). Os principais investidores de primeira perda nas CDOs para arbitragem conhecidas pelo mercado são as companhias de seguro, alguns bancos e administradores de ativos.

Além da aplicabilidade na melhoria de rendimentos e no gerenciamento de balanços patrimoniais, as CDOs acabam também sendo usadas para criar alguma liquidez no que seriam ativos sem liquidez. Por exemplo, se pegarmos empréstimos bancários sem liquidez pelo fato de que cada venda requer aprovação do tomador do empréstimo, e securitizarmos, suas características de risco serão mais fáceis de serem comercializadas, já que o SPV terá emitido notas que são compradas e vendidas no mercado. Além disso, Bonfim (2007) descreve que as estruturas de CDOs permitem, por meio do processo de tranches, a criação de novos ativos com perfis específicos que podem de uma melhor forma satisfazer as necessidades individuais e as tolerâncias ao risco dos investidores institucionais.

Lewis (2011) ressalta que durante o processo de formação da crise de 2008, o Goldman Sachs criou um título tão opaco e complexo que ele seria um mistério mal compreendido pelos investidores e agências de classificação de crédito até os dias atuais - a CDO (obrigação de dívida garantida) sintética lastreada em títulos hipotecários subprime sintéticos. Na visão de Lewis (2011, p. 99), a CDO havia sido inventada para redistribuir o risco de inadimplência de títulos governamentais ou corporativos e agora estava sendo remodelada para disfarçar o risco dos empréstimos hipotecários subprime. A lógica dessa CDO era a mesma dos títulos hipotecários originais.

Em um título hipotecário eram reunidos milhares de empréstimos e, supondo que seria pouco provável que todos desandassem de uma só vez, criava-se uma torre de títulos, em que tanto o risco quanto o retorno diminuíam à medida que se subia os andares. Em um CDO, centenas de títulos hipotecários diferentes - em geral, aqueles nos andares mais baixos e de maior risco da torre original - eram agrupados e utilizados para construir uma torre inteiramente nova de títulos (LEWIS, 2011, p.100). Teoricamente, pode não parecer sensato usar os andares de uma torre de dívida para construir outra forma de dívida, mas, na prática, o fato de serem os andares mais próximos de uma inundação, sendo os primeiros a assumir prejuízos, tornavam sua classificação de crédito (BBB) não atraente para comercialização. Dessa forma, a possibilidade de reclassificar essa nova dívida para uma classificação melhor interessava aos bancos, mesmo que fosse feito de forma desonesta ou artificial.

Lewis (2011) afirma que o Goldman Sachs conseguiu persuadir as agências de classificação de risco que esses títulos reempacotados não eram exatamente iguais aqueles de má 
avaliação, mas que, na verdade, eram uma "outra carteira diversificada de ativos". o autor ainda destaca que a CDO era, na verdade, um serviço de lavagem de crédito para os residentes da classe média baixa norte-americana. Para Wall Street, era uma máquina que transformava chumbo em ouro. Para esse caso específico do Goldman, as agências de classificação de risco tornaram $80 \%$ da nova torre de dívida (chumbo) em classificação AAA (ouro).

Para transparecer melhor o porquê dessa forte opinião de Michael Lewis, é importante entender que, ao longo da formação da crise, o tamanho do mercados de títulos cresceu exponencialmente. Randolph e McKay (2015) afirma que foi durante um Fórum Americano de Securitização, em Las Vegas, que Steve Eisman tomou ciência completa do tamanho da crise e das consequências que estavam por vir. E a informação que mais mexeu com o gestor da FrontPoint foi que um gerente de CDOs de um determinado banco americano relatou: que o mercado de títulos não apenas era maior que o mercado de hipotecas, mas que, já em 2005, representava 20 vezes seu tamanho. Pensando numa estrutura direta de vínculo entre hipotecas-MBS-CDO-CDO sintético, Eisman entendeu que 50 milhões de dólares em títulos hipotecários representavam 1 bilhão de dólares em CDOs sintéticos. $O$ risco de não pagamento e cumprimento de todas as garantias era evidente. A partir dessas informações, Randolph e McKay (2015) afirmam que a FrontPoint operou vendido meio bilhão de dólares.

A ideia de apostar contra o mercado de títulos hipotecários subprime não era novidade para Eisman. Ela foi inicialmente indicada e sugerida por Michael Burry em seus estudos de indicadores do mercado imobiliário, e chegou até as mãos de Steve Eisman através de uma apresentação feita por um operador peculiar do Deutsche Bank chamado Greg Lippman, em fevereiro de 2006, sob o título de "Vender a descoberto tranches de mezanino de hipotecas residenciais". A ideia sugerida era de basicamente comprar CDSs dos piores tipos de títulos hipotecários subprime, classificados como BBB. Lippman defendia sua ideia baseada em tudo que Burry já tinha exposto e poucos davam atenção: "desde 2000, as pessoas cujas casas haviam subido de preço entre $1 \%$ a $5 \%$ tinham quase quatro vezes mais chances de não conseguir pagar seus empréstimos do que as pessoas cujas casas valorizaram mais de 10\%" (LEWIS, 2011, p. 91). Entende-se assim, que milhões de norte-americanos estavam dependendo que os preços dos imóveis residenciais aumentassem drasticamente para terem condições de pagarem suas hipotecas, o que permitiria a eles fazerem empréstimos ainda maiores. 0 resumo da historia era que caso $o$ valor das casas parassem de subir em ritmos elevados, milhares de pessoas deixariam de pagar seus empréstimos imobiliários.

Conforme Lewis (2011), a apresentação de Lippman e as informações obtidas durante o Fórum Americano de Securitização entre 2005 e 2006 foram fundamentais para a decisão de vender a descoberto feita pela FrontPoint. Porém, o que realmente mudou o jogo para esse grupo de investidores que enxergou a realidade decadente do mercado imobiliário americano foi a existência de um instrumento financeiro chamado Credit Default Swap (CDS).

31 Um credit default swap é um acordo bilateral entre um comprador e um vendedor de proteção de crédito (BONFIM, 2007, p.76). Na sua forma padrão (vanilla), o comprador dessa proteção concorda em fazer pagamentos periódicos sobre uma predeterminada periodicidade ao vendedor da proteção. A periodicidade definida é o vencimento do CDS. Em troca, a parte que está vendendo essa proteção se compromete a fazer um pagamento em caso de evento de crédito (default) da terceira parte (entidade de referência). Destaca- 
se que o CDS se aproxima de alguns seguros tradicionais. Conforme pode-se observar na Figura 3, o comprador da proteção está adquirindo uma espécie de seguro contra inadimplência da parte que está vendendo a proteção.

Figura 3 - Exemplo de um Credit Default Swap.

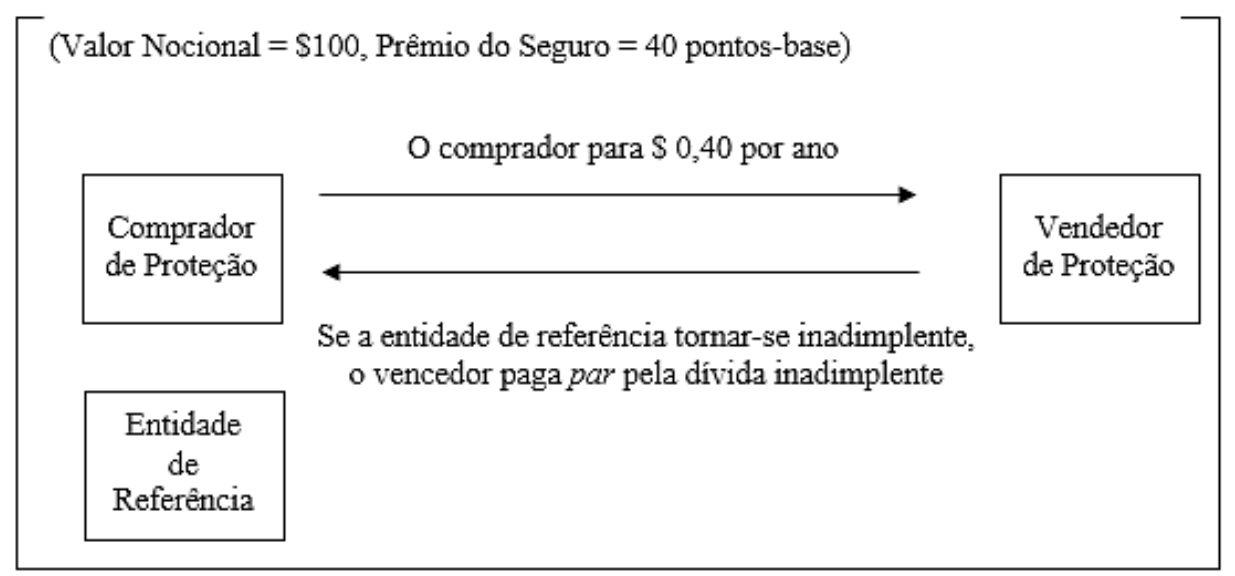

Fonte: (BONFIM, 2007, p. 77). proteção por meio de credit default swaps mesmo quando eles não possuem exposição à entidade de referência em questão. Nesse caso, comprar proteção é semelhante a vender a descoberto a dívida da entidade de referencia. E esse foi o caso de Michael Burry. Lewis (2011, p.75), afirma que no dia 19 de maio de 2005, Mike Burry fechou suas primeiras transações de hipotecas subprime. Ele comprou US\$60 milhões em CDSs do Deutsche Bank US $\$ 10$ milhões para cada um de seis títulos diferentes. Eram chamados de "valores mobiliários de referência". Burry contou que leu dezenas de prospectos e examinou centenas de outros procurando pelos grupos de hipotecas mais duvidosas pois ele sabia que não se comprava derivativo de crédito para um mercado inteiro de títulos.

gestor da Scion Capital, os bancos não viam diferença entre os títulos hipotecários subprime. 0 preço dos seguros não foi determinado por análises independentes, mas sim pelas classificações conferidas pelas agências de classificação. Se alguém quisesse 
comprar CDS sobre uma tranche AAA, supostamente sem risco, poderia pagar até 20 pontos base $(0,2 \%)$; já nas tranches de maior risco, classificadas como A, poderia pagar 50 pontos base $(0,5 \%)$; e naquelas menos seguras ainda, classificadas como BBB, 200 pontos base, ou seja, 2\%. "As tranches classificadas como BBB - que valeriam zero se o pool de hipotecas subjacentes tivesse um prejuízo de apenas $7 \%$ - eram o que ele procurava.

Depois de anos de estudo, em poucas semanas Michael Burry havia comprado várias centenas de milhões de dólares em CDS de meia dúzia de bancos, em lotes de US $\$ 5$ milhões. Segundo ele, nenhum dos vendedores parecia se importar muito com os títulos que estavam assegurando. Burry sempre seguiu um raciocínio conservador mesmo na compra de CDS. Encontrou um pool com $100 \%$ de hipotecas com amortização negativa e taxa flutuante de juros, onde os tomadores de empréstimos poderiam escolher a opção de não pagar juros e simplesmente acumular uma dívida cada vez maior até entrarem em inadimplência. Essas negociações envolveram fatos curiosos, como conta Lewis: "O Goldman Sachs não só lhe vendeu o seguro do grupo de hipotecas, como também enviou uma nota parabenizando-o por ser a primeira pessoa, dentro ou fora de Wall Street, a ter comprado CDS para aquele item específico" (2011, p.78).

37 A FrontPoint, liderada por Steve Eisman, também comprou CDS para operar vendido no mercado. "A beleza dos CDSs era que eles resolviam o problema do tempo. Eisman não precisava mais adivinhar exatamente quando o mercado hipotecário subprime entraria em colapso" (LEWIS, 2011, p. 92). Ele já tinha certeza que entraria. Sua carreira, sua historia de vida, e todas as reuniões, conversas e fóruns que ele participou lhe davam essa certeza. 0 mercado estava tomado por uma estrutura auto-destrutiva.

Uma das peculiaridades envolvendo a longa historia de negociações de Michael Burry era que, pelo fato de ele ter $100 \%$ de autonomia em seu contrato como gestor da Scion Capital, ele fechou todos os contratos já citados de maneira confidencial para que, em outubro de 2005 , em uma carta aos investidores contar-lhes que eles detinham pelo menos US\$ 1 bilhão em CDS de títulos hipotecários subprime. Lewis (2011) conta que nessa famigerada carta - que causou o maior stress de toda carreira de Burry no mercado financeiro ele escolheu encerrar seu texto com a seguinte frase: "Às vezes, os mercados erram feio".

Os detalhes aprofundados das negociações eram mais complicados, mas a essência era simples. Apostar contra o mercado imobiliário. Contra os pilares da economia americana. Eisman e Burry não foram os únicos. Conforme afirma Lewis (2011), quando os indicadores já não demonstravam mais volta, na virada de 2006 para 2007, até os próprios bancos fizeram de tudo para ganhar com vendas a descoberto. A máquina de ganhar dinheiro foi montada: transformava muitos empréstimos de risco em uma pilha de títulos, a maioria dos quais classificados como AAA, depois pegava os títulos remanescentes com a pior avaliação e os transformava em CDOs AAA. Como não era possível estender os empréstimos imobiliários de forma rápida o bastante para criar um número suficiente de títulos com classificação mais baixa, usava os CDSs para replicar o pior dos títulos existentes, muitas e muitas vezes (LEWIS, 2011, p. 104).

\section{Os impactos da crise}

Em 22 de outubro de 2008, quando a crise já tinha impactado fortemente a população norte-americana e gigantes do setor financeiro, Deven Sharma, presidente da Standard and Poor's (S\&P) em depoimento perante o congresso norte-americano pronunciou a 
seguinte frase: "Praticamente ninguém - proprietários de imóveis, instituições financeiras, agências de classificação de risco, reguladores ou investidores - previu o que está ocorrendo" (LEWIS, 2011, p. 269). O head de uma das principais empresas responsáveis pela bagunça estrutural do sistema americano, no que tange os títulos hipotecários, disse em seu depoimento judicial que ninguém previu que a crise poderia acontecer. Ele não deve ter ouvido falar das operações de CDS envolvendo a Scion Capital e a FrontPoint, replicadas incontáveis vezes no mercado durante 2006 e 2007, tanto por investidores, quanto por instituições financeiras.

41 Falando na empresa de Eisman, "no final de 2007, as apostas da FrontPoint contra as hipotecas subprime haviam tido um retorno tão espetacular que eles dobraram o tamanho de seu fundo, de um pouco mais de US\$700 milhões para US\$1,5 bilhão" (LEWIS, 2011, p. 270). Steve Eisman sempre foi transparente em suas entrevistas, e contou publicamente que a raiva e os sentimentos que abasteceram sua aposta não foi direcionada à todo sistema financeiro, mas às pessoas no topo da hierarquia, que conheciam o sistema $\mathrm{e}$ deveriam se preocupar com os clientes que pagavam seus bônus milionários.

42 Greg Lippman, o operador de títulos do Deustche Bank que, sabendo de todas as informações, quis lucrar com os dois lados da historia, obviamente, também saiu ganhando. Randolph e McKay (2015) conta que ele recebeu US\$47 milhões em 2007, mas, dessa quantia, quase metade, US $\$ 24$ milhões, foi em ações restritas que ele não poderia receber a menos que ficasse mais alguns anos no Deustche Bank. Nessa história, não devese esquecer da figura marcante de Michael Burry. De fato, ele foi o primeiro profissional de finanças nos Estados Unidos que, publicamente, divulgou material alertando sobre os problemas que surgiam no mercado imobiliário americano. Além disso, foi ele que tomou a iniciativa de realizar uma venda a descoberto com o Goldman Sachs que marcou o começo de um mercado bastante ativo entre os anos de 2005 a 2008.

43 A história contará que qualquer investidor que tivesse ficado com a Scion Capital desde o início, em $1^{\circ}$ de novembro de 2000 , até junho de 2008, teria ganho, descontados os impostos e despesas, $498,34 \%$. Lewis (2011) descreve que o ganho bruto registrado pela Scion ficou na faixa aproximada de $726 \%$. Conforme consta no site do Federal Reserve System (FED), o índice S\&P 500 retornou apenas um pouco mais de $2 \%$ no mesmo período. Somente em 2007, Burry rendera aos investidores da Scion Capital US\$750 milhões. Os mesmos investidores que, durante anos, foram contrários as estratégias de compra de CDS de títulos subprime, e pressionavam para conseguirem retirar seus recursos do fundo, além de requererem veementemente a troca de Burry como gestor de seus recursos.

Mas como em qualquer crise, os estragos costumam ser maiores que os ganhos. De acordo com o Fundo Monetário Internacional (FMI) as perdas relacionadas à crise financeira internacional chegaram a US\$ 1 trilhão. Segundo dados da britânica BBC, o ano de 2008 marcou para sempre a historia do mercado financeiro mundial, começando em março, pela oficialização do resgate do Bear Sterns, banco que, como qualquer outra empresa de Wall Street, passou os primeiros anos do século XXI aumentando o tamanho de suas apostas feitas com cada dólar de seu capital possível. Em cinco anos, a alavancagem do Bear Sterns tinha passado de 20:1 para 40:1. O governo americano concedeu US $\$ 30$ milhões como garantia contra as perdas do banco, facilitando, dessa forma, a compra da operação pelo JP Morgan Chase. As ações do Bear Sterns foram vendidas ao JP, inicialmente, por US\$2 cada. Porém, o valor foi revisto para US\$10 durante o fechamento da operação, o que aconteceu em maio de 2008. Em setembro de 2008, o Lehman Brothers pediu falência, citando uma dívida bancária de US\$613 bilhões, sendo US $\$ 155$ bilhões em dívidas aos 
detentores de títulos e ativos avaliados em US\$639 bilhões. No mesmo dia, o tradicionalíssimo Merrill Lynch anunciou US\$55,2 bilhões em prejuízos nos CDOs lastreados em títulos subprime. Porém, eles tiveram mais sorte e não precisaram pedir concordata, pois foram comprados pelo Bank of America, em uma transação de, aproximadamente, US $\$ 50$ bilhões.

No final de 2008, Henry Paulson, secretário do tesouro americano, conseguiu aprovar um pacote de emergência de US $\$ 700$ bilhões, chamado de Trouble Assets Relief Program (TARP). Esse dinheiro basicamente foi usado para comprar ativos podres do setor imobiliário e injetar dinheiro público em bancos como o Goldman Sachs e o Morgan Stanley. De acordo com a BBC, mesmo com o dinheiro do contribuinte americano em cofres, as duas empresas, ainda em setembro de 2008, aprovaram a mudança de status de bancos de investimentos para holdings num movimento que marcou o fim de uma era em Wall Street. No mesmo período, o Washington Mutual, um dos maiores nomes do setor de hipoteca norte-americano, com ativos avaliados em US\$307 bilhões, foi fechado por agências reguladoras e vendido ao JP Morgan Chase.

Dentro de tantos impactados no setor financeiro, talvez aquele que tenha mais sentido de fato a crise tenha sido o povo norte-americano. Durante o período crítico, segundo BBC Brasil (2009), o desemprego americano passou de 10\%. Mais de 8,7 milhões de pessoas perderam seus empregos, e mais da metade dos adultos sofreram com cortes no salário ou tiveram que trabalhar em tempo parcial. Após o caos, o S\&P 500 perdeu metade do seu valor e o Dow Jones atingiu seu nível mais baixo desde abril de 1997.

Em resumo, a população perdeu emprego, renda e moradia e pagou a conta. As instituições financeiras envolvidas não foram diretamente responsabilizadas e, aquelas que faliram, foram ou compradas e incorporadas por sobreviventes do setor, ou resgatadas com dinheiro público pelo governo americano. Para John Gutfreund, ex-CEO do Salomon Brothers, a causa de toda crise residiu na ganância. Tanto dos investidores quanto dos banqueiros. Já Lewis (2011, p. 303), trouxe uma provocação interessante: Quais são as chances de as pessoas tomarem decisões inteligentes sobre investimentos se elas não precisam dessas decisões, se conseguem ficar ricas fazendo escolhas idiotas?.

\section{Procedimentos Metodológicos}

Para classificação da pesquisa tomou-se como base a classificação metodológica proposta por GIL (2010). Diante disso, verifica-se que a pesquisa realizada sobre os derivativos de crédito e os demais instrumentos financeiros que possibilitaram perdas e ganhos para diversos investidores na crise de 2008 está classificada da seguinte forma: quanto à natureza foi uma pesquisa básica, pois não apresenta finalidades imediatas, a fim de gerar produtos, pois se pretendeu gerar conhecimentos para registros bibliográficos ou processos. Em relação à abordagem da pesquisa, nota-se caráter qualitativo, pois o trabalho teve o ambiente natural como fonte direta para coleta de dados, ou seja, a pesquisa não requereu o uso de técnicas estatísticas e o pesquisador foi o instrumentochave, através de interpretação de fenômenos, atribuição de significados e análise direta.

Acrescenta-se ainda que a pesquisa desenvolvida foi, quanto aos objetivos, explicativa. GIL (2010) afirma que quando uma pesquisa busca explicar as causas, fazendo uso de registro, análise e classificação de fenômenos e fatos ela se caracteriza como pesquisa explicativa. Ou seja, a pesquisa teve como preocupação central identificar os fatores que 
determinaram ou que contribuíram para a ocorrência de fenômenos específicos. Segundo o autor: "aprofunda o conhecimento da realidade por explicar a razão, o porquê das coisas" (GIL, 2010, p. 28).

Já, em relação aos procedimentos técnicos, o método escolhido foi, tanto a pesquisa bibliográfica, quanto a documental. Como boa parte do material elaborado foi desenvolvido levando em consideração publicações existentes, como artigos científicos e livros relacionados com a temática estabelecida, um levantamento do estado da arte foi necessário neste estudo. Além disso, por se tratar de um tema recente, e por vezes, ainda atual, foi feito uso de materiais que ainda não receberam tratamento analítico científico, como, por exemplo, filmes e documentários, caracterizando, também um uso de pesquisa documental para realização deste trabalho.

\section{Análise e Discussão dos Resultados}

51 Ao longo de todo artigo, o objetivo de estudar os instrumentos financeiros que possibilitaram grandes perdas e consideráveis ganhos com a crise do subprime esteve presente. De acordo com Cintra e Cagnin (2007), o que aconteceu com o crédito hipotecário americano foi uma legítima farra. Para que simples instrumentos financeiros como títulos hipotecários se transformassem em estruturas complexas como CDOs sintéticos, foi necessário um aumento considerável dos empréstimos de alto risco ( subprime) dentro dos empréstimos hipotecários, conforme apresentado na Figura 4.

Figura 4 - Participação do subprime nos empréstimos hipotecários.

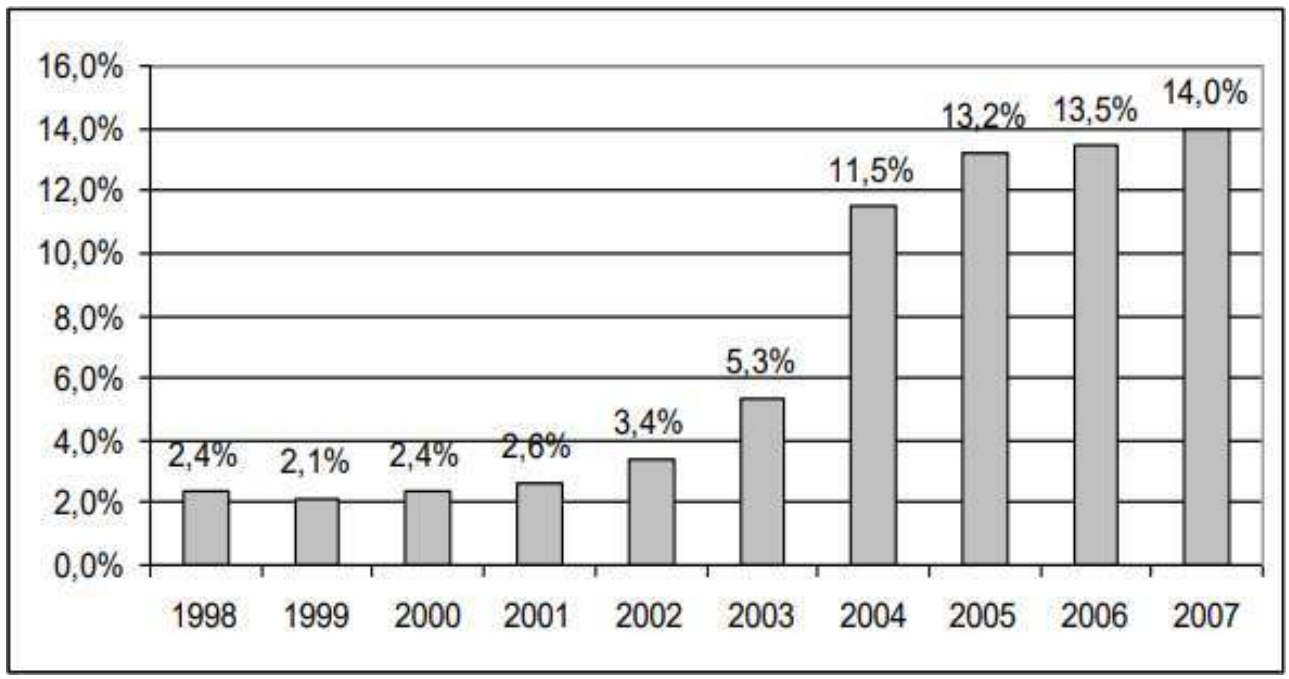

Fonte: (POMBAL, 2010).

52 A Figura 4 evidencia o movimento de crescimento considerável do subprime nas estruturas americanas, a partir de 2004. O caso analisado permite constatar desequilíbrios estruturais que evoluíram para um desastre econômico global, conforme expõem Gontijo (2011, p.20). Embora a crise financeira tenha origem ou nasça dos próprios desequilíbrios e das formas contraditórias de funcionamento dos mercados e do sistema econômico, seu ponto de partida se dá em arranjos mal estruturados para acomodar essas contradições e friç̧ões, podendo ganhar velocidade e intensidade se as estruturas montadas nesses arranjos forem favoráveis para sua potencialização, tornando os efeitos de determinadas 
políticas econômicas inócuas para revertê-la e impedir que a economia caminhe para a recessão, antes que todos os estragos sejam por ela produzidos.

Mesmo que Gontijo (2011) não tenha exemplificado em seu livro, os arranjos mal estruturados a que ele se refere, são possíveis de serem ilustrados quando observamos que hedge funds como a Scion Capital, geridas por um único profissional, atingiram crescimentos extraordinários durante a crise de 2008, simplesmente, fazendo correta utilização de derivativos de crédito como proteção contra calotes, no caso de credit default swaps (CDS), enquanto que empresas centenárias como o Lehman Brothers faliram com mais de US\$ 150 bilhões em dívidas somente para detentores de títulos, como, por exemplo, Mortgage Backed Securities (MBS).

Os derivativos de crédito, de fato, foram uma fortaleza para os agentes de mercado que enxergaram a possibilidade de ganho através da crise do subprime. O CDS como instrumento central permitiu que participantes do mercado comprassem proteção mesmo quando não possuíssem qualquer exposição à entidade de referência que os swaps estavam se referindo. Dessa forma, ao comprar proteção por meio do credit default swap os investidores estavam vendendo a descoberto a dívida enorme de bancos que passaram anos aumentando a exposição ao risco de uma forma mal planejada. Conforme Bonfim (2007), em geral, esse instrumento financeiro é utilizado tanto para comprar proteção e restringir exposições ao risco de crédito de devedores em específico, assim como, para servir como fonte adicional de renda para aqueles que vendem a proteção, geralmente, seguros que seus ativos tem valor e risco controlado.

É valido ressaltar que o crescimento do mercado de empréstimos subprime acontecia ao mesmo tempo em que o governo americano incrementava os juros, impossibilitando a boa gestão dos empréstimos feitos para clientes com pouquíssima renda. Esse movimento dissonante da realidade foi crucial para que os títulos hipotecários compostos por empréstimos de alto risco perdessem todo seu valor no mercado, mesmo as agências de classificação de risco tentando dizer o contrário. Além disso, com o não pagamento das hipotecas e a recomercialização dessas dívidas em títulos como a Collateralized Debt Obligation (CDO), o cenário de derrocada se tornou cada vez mais natural.

As principais economias globais sofreram fortemente com a quebra no sistema bancário americano, mas países como, por exemplo, o Brasil, fez muito pouco para mudar este cenário. A nível local, o que pode ser destacado foi a ação conjunta da Federação Brasileira de Bancos (FEBRABAN), da Central de Custódia e de Liquidação Financeira de Títulos (CETIP) e da Bolsa (BM\&FBOVESPA) para criação da Central de Exposição aos Derivativos (CED). Conforme informações divulgadas pelo site da Bolsa de Valores (B3) do Brasil, A CED, desde a sua criação, na virada de 2010 para 2011, tem como principal objetivo possibilitar a instituições financeiras participantes acompanhar melhor a performance de seus clientes no uso dos derivativos - proteção, especulação ou arbitragem - e, consequentemente, realizar uma gestão mais eficiente do seu risco.

57 A CED emite um relatório para auxiliar as instituições financeiras (contraparte nas operações) na identificação de alavancagem e na gestão adequada de sua exposição. Quando necessário, os relatórios emitidos pela Central de Exposição de Derivativos podem propor, por exemplo, uma recompra ou liquidação antecipada. Ao mesmo tempo, analisando qualquer relatório público anual das principais instituições financeiras brasileiras, é possível observar que o volume de transação envolvendo ativos complexos e de alta alavancagem, como o caso de derivativos, continua crescendo consideravelmente. 


\title{
Conclusão
}

\begin{abstract}
mesmo tempo em que o governo americano incrementava os juros, impossibilitando a boa gestão dos empréstimos feitos para clientes com menor renda. 0 movimento do mercado foi crucial para que os títulos hipotecários compostos por empréstimos de alto risco perdessem todo seu valor, mesmo as agências de classificação de risco tentando dizer o contrário. Além disso, com o não pagamento das hipotecas e a recomercialização dessas dívidas em títulos como a CDO, o cenário de derrocada se tornou cada vez mais natural. Como sugestão para pesquisas futuras, recomenda-se analisar o contexto da atual crise econômica de países, como por exemplo, a Venezuela, com o objetivo de identificar os elementos que podem desencadear uma crise hipotecária semelhante à crise ocorrida nos Estados Unidos da América em 2008.
\end{abstract}

Analisar um evento de repercussão mundial, sob o olhar técnico das finanças é uma oportunidade única para entender a fundo as estruturas que desenvolveram a crise de 2008. É importante salientar que não se buscou apreciar algum juízo de valor sobre os ganhos e perdas relativos a crise do subprime. A luz que guiou este trabalho foi a de apresentar uma reflexão sobre a temática. Além de observar que as causas estruturais e as graves consequências envolvendo a crise imobiliária de 2008 continuam obscuras em diversos setores da sociedade.

instituições financeiras não darem atenção durante anos para os indicadores que evidenciavam problemas no mercado imobiliário foi o gatilho para um grupo de investidores enxergarem o desastre estrutural que estava montado e buscar ganhar recursos com isso. Ao mesmo tempo em que a máquina de dinheiro estava montada, a maior parte da população sofria com as recessões econômicas e a ameaça diária de perda de renda e emprego.

\section{BIBLIOGRAFIA}

BBC. Cronologia da Crise. Disponível em: http://www.bbc.com/portuguese/noticias/20 09/09/090902_aftershock_timeline_noflash>. Acesso em: 28 fev. 2018.

BBC Brasil. Desemprego nos EUA ultrapassa 10\% pela $1^{\underline{a}}$ vez desde 1983. 2009. Disponível em: < http://www.bbc.com/portuguese/noticias/2009/11/091106_euadesempregoml>. Acesso em: 02 março. 2018.

BESSADA, O.; BARBEDO, C.; ARAÚJO, G. Mercado de derivativos no Brasil. Rio de Janeiro: Record, 2005.

BONFIM, A. N. Derivativos de crédito e outros instrumentos. Rio de Janeiro: Elsevier, 2007. 
CINTRA, M. A. M.; CAGNIN, R. F. Devolução da estrutura e da dinâmica das estruturas norteamericanas. Econômica, Rio de Janeiro, v.9, n. 2, p. 296 - 338, dezembro/2007.

DE FREITAS, K. A.; DA SILVA, D. F.; DE FIGUEIRÊDO, L. Crise Do Subprime: As Perspectivas Do Pensamento Neoclássicas E Comportamentais. Revista FSA, v. 13, n. 2, 2016.

FANG, H.; LU, R.; SU, C. Impact of the Subprime Crisis on Commercial Banks' Financial Performance. Panoeconomicus. 2013.

FIGUEIREDO, A. C. Introdução aos Derivativos. São Paulo: Cengage Learning, 2016.

GIL, A. C. Como elaborar projetos de pesquisa. São Paulo: Atlas, 2010.

GOLDMAN, D. Crise dos EUA elimina 1,5 milhão de vagas de emprego. Disponível em: <http:// www1.folha.uol.com.br/mercado/2017/10/1925441-crise-dos- estados-unidos-elimina-15milhao-de-vagas-de-emprego.shtml>. Acesso em: 20 nov. 2017.

GONTIJO, C.; OLIVEIRA, F. A. Subprime: os 100 dias que abalaram o capital financeiro mundial e os efeitos da crise sobre o Brasil. Belo Horizonte: Corecon MG, 2011.

HELIO, B. TARP destina-se ao setor financeiro, diz Paulson. Disponível em:<http:// economia.estadao.com.br/noticias/geral,tarp-destina-se-ao-setor-financeiro-diz- paulson,288874 >. Acesso em: 05 mar. 2018.

LEWIS, M. A jogada do século: A história do colapso financeiro de 2008 que deu origem ao filme A Grande Aposta. Editora Best Seller, 2011.

KARTIO, M. A. et al. Impact of Global Financial Crisis on the Performance of Commercial Banks of Pakistan-A Case Study of MCB Bank Limited. 2017.

KRUGMAN, P. Como os economistas puderam errar tanto? Econômica, Rio de Janeiro,2009.

NAPPI, J. F. et al. Sistema bancário e regulação no Brasil: reflexões a partir da crise financeira internacional e da adequação à Basileia III. 2017.

POMBAL, C. S. A. Derivativos, Alavancagem e a Crise de 2008. 2010. 98 f. Dissertação (Mestrado em Gestão Empresarial) - Escola Brasileira de Administração Pública e de Empresas, Fundação Getúlio Vargas, Rio de Janeiro, 2010.

RODRIGUES, R. A. Derivativos de crédito: aspectos jurídicos. Tese de Doutorado. Universidade de São Paulo,2015.

RICCI, M. N.; TIRELLI, P. Subprime mortgages and banking in a DSGE model. 2017.

PORTAL ITAÚ. 2014: Relatório Anual Consolidado. Disponível em: <https://www.ita u.com.br/ _arquivosestaticos/RI/pdf/2014RAO_port.pdf>. Acesso em: 21 dez. 2017.

POZZI, S. Bolha Imobiliária: dez anos do gatilho da crise que parou o mundo. Disponível em: < https://brasil.elpais.com/brasil/2017/08/05/economia/1501927439_342599. html>. Acesso em: 20 nov. 2017.

RANDOLPH, C.; MCKAY, A. The Big Short. Disponível em: <http://la- screenwriter.com/wpcontent/uploads/2016/01/the-big-short.pdf>. Acesso em: 18 ago. 2017.

SILVA, B. A. O.; PINESE, H. P. A Crise Financeira Internacional (2008) e o Efeito dos Derivativos Cambiais: a operação de target forward da Aracruz Celulose. Revista de Administração, Contabilidade e Economia da FUNDACE, Ribeirão Preto, v. 1, p. 1-13, dezembro/2010.

SHIRAI, S. The impact of the US subprime mortgage crisis on the world and East Asia. 2009. 
SIQUEIRA, A. S.; IGLESIAS, F. P. A importância da Central de Exposição de Derivativos (CED) para a Gestão do Risco de Crédito do Mercado Financeiro. Disponível em: <http:// resenhadabolsa.com.br/portfolio-items/a-importancia- da-central-de-exposicoes-de-derivativosced-para-a-gestao-do-risco-de-credito-do-mercado- financeiro/>. Acesso em: 22 dez. 2017.

THE BIG SHORT. Direção: Adam Mckay.Produção: Plan B Entertainment. Roteiro: Adam Mckay e Charles Randolph: Paramount Pictures,2015.

\section{RESUMOS}

$\mathrm{O}$ artigo objetiva analisar como os instrumentos e estruturas financeiras permitiram que o setor mais sólido e representativo dos Estados Unidos da América gerasse uma crise sem precedentes. As origens da crise imobiliária de 2008 remontam a criação e difusão dos títulos hipotecários ( mortgage backed securities) na mesa do Salomon Brothers nos anos 70, passam pela incorporação de empréstimos de alto risco (subprime) ao longo dos últimos 30 anos a fim de rentabilizar os títulos e chegam até o reempacotamento de hipotecas não pagas por meio dos títulos lastreados em dívidas, popularmente conhecidos como CDOs (Collateralized Debt Obligation). Ao passo que o mundo noticiava e comentava as perdas envolvendo a crise, que em 2008 já haviam superado o valor de US\$ 1 trilhão, foi possível constatar que um grupo de investidores atento aos indicadores acabou apostando contra o sistema e saiu ganhando. Fundos como a Scion Capital e a FrontPoint Partners acompanharam, por anos, a derrocada na qualidade do que estava sendo comercializado nos bancos e revendido incontáveis vezes. A queda na qualidade dos empréstimos hipotecários era evidente e um derivativo de crédito, em particular, o credit default swap, foi usado como seguro contra calote de instituições e títulos que não faziam parte da carteira de ativos dos investidores. Os contratos de swaps garantiram tempo e proteção aos investidores, que, ao longo da crise, aguardaram seus milhões de retorno, enquanto enxergavam a derrocada de gigantes como Lehman Brothers e Merrill Lynch, assim como, a derrocada de milhares de pessoas, sem emprego e sem moradia.

The article aims to analyze how the financial instruments and structures allowed the most solid and representative sector of the United States of America to generate an unprecedented crisis. The origins of the 2008 housing crisis go back to the creation and diffusion of mortgage backed securities at the Salomon Brothers table in the 1970s, through the incorporation of subprime loans over the last 30 years in order to monetize bonds and even repackaging unpaid mortgages through debt-backed securities, popularly known as CDOs (Collateralized Debt Obligation). While the world was reporting and commenting on the losses involving the crisis, which in 2008 had already surpassed the value of US \$ 1 trillion, it was possible to see that a group of investors, looking at the indicators, ended up betting against the system and won. Funds such as Scion Capital and Front Point Partners have been tracking for years the quality of what was being marketed at banks and resold countless times. The decline in the quality of mortgage loans was evident and a credit derivative, in particular the credit default swap, was used as insurance against defaulting institutions and securities that were not part of the portfolio of investor assets. The swap contracts ensured time and protection for investors who, over the course of the crisis, waited for their millions of return as they saw the collapse of giants like Lehman Brothers and Merrill Lynch, as well as the collapse of thousands of people without jobs and without housing.

El artículo tiene como objetivo analizar cómo los instrumentos y estructuras financieras permitieron que el sector más sólido y representativo de los Estados Unidos de América generara una crisis sin precedentes. Los orígenes de la crisis inmobiliaria de 2008 se remonta à la creación 
y difusión de los títulos hipotecarios en la mesa de Salomon Brothers en los años 70, pasando por la incorporación de préstamos de alto riesgo (subprime) a lo largo de los últimos 30 años a fin de rentabilizar los títulos y llegan hasta el reempaquete de hipotecas no pagadas por medio de los títulos respaldados en deudas, popularmente conocidos como CDOs (Collateralized Debt Obligation). Al paso que el mundo noticiaba y comentaba las pérdidas involucrando la crisis, que en 2008, ya habían superado el valor de US \$ 1 billón, fue posible constatar que un grupo de inversores, atento a los indicadores, acabó apostando contra el sistema y salió ganando. Fondos como Scion Capital y FrontPoint Partners acompañaron, por años, el derrocamiento en la calidad de lo que estaba siendo comercializado en los bancos y revendido incontables veces. La caída en la calidad de los préstamos hipotecarios era evidente y un derivado de crédito, en particular, el credit default swap, fue utilizado como seguro contra el incumplimiento de instituciones y títulos que no formaban parte de la cartera de activos de los inversores. Los contratos de swaps garantizaron tiempo y protección a los inversores que, a lo largo de la crisis, aguardaron sus millones de retorno, mientras veían el derrocamiento de gigantes como Lehman Brothers y Merrill Lynch, así como el derrocamiento de miles de personas, sin empleo y sin vivienda.

L'article vise à analyser comment les instruments financiers et les structures financières ont permis au secteur le plus solide et le plus représentatif des États-Unis d'Amérique de générer une crise sans précédent. Les origines de la crise du logement de 2008 remontent à la création et à la diffusion de titres adossés à des créances hypothécaires à la table des Salomon Brothers dans les années 1970, à travers l'incorporation de prêts subprime au cours des 30 dernières années afin de monétiser obligations et même reconditionner les hypothèques impayées à travers des titres adossés à des créances, communément appelées CDO (Collateralized Debt Obligation). Tandis que le monde faisait rapport et commentait les pertes liées à la crise, qui avait déjà dépassé la valeur de 1000 milliards de dollars en 2008, il était possible de voir qu'un groupe d'investisseurs, en regardant les indicateurs, finissait par parier contre le système et gagnait. Des fonds tels que Scion Capital et FrontPoint Partners suivent depuis des années la qualité de ce qui était commercialisé dans les banques et revendu d'innombrables fois. La baisse de la qualité des prêts hypothécaires était évidente et un dérivé de crédit, en particulier le swap sur défaillance de crédit, a été utilisé comme assurance contre les institutions défaillantes et les titres qui ne faisaient pas partie du portefeuille d'actifs des investisseurs. Les contrats de swap ont assuré temps et protection aux investisseurs qui, au cours de la crise, ont attendu leurs millions de retours en voyant l'effondrement de géants comme Lehman Brothers et Merrill Lynch, ainsi que l'effondrement de milliers de personnes sans emploi et sans logement.

\section{ÍNDICE}

Mots-clés: Crise 2008, Subprime, Titres hypothécaires, Dérivés de crédit, Titres de créance.

Palabras claves: Crisis de 2008, Subprime, Títulos hipotecarios, Derivados de crédito, Títulos de las deudas.

Palavras-chave: Crise de 2008, Subprime, Títulos hipotecários, Derivativos de crédito, Títulos lastreados em dívidas

Keywords: 2008 Crisis, Subprime, Mortgage Securities, Credit Derivatives, Debt Securities. 


\section{AUTORES}

\section{MARCOS RUPPELT}

Engenheiro de Produção pela Universidade Federal de Santa Maria (UFSM). MBA em Finanças e controladoria pela UniRitter Laureate Internacional Universities

\section{ANDRÉ BRUM MISSAGGIA}

Engenheiro de Produção pela Universidade Federal de Santa Maria (UFSM). Mestrando em Engenharia de Produção pela UFSM

\section{BRUNO MIRANDA DOS SANTOS}

Engenheiro de Produção pela Universidade Federal de Santa Maria (UFSM). Mestre em Engenharia de Produção pela UFSM. Doutorando em Engenharia de Produção pela Universidade Federal do Rio Grande do Sul (UFRGS)

\section{FRANCO DA SILVEIRA}

Engenheiro Mecânico pela Universidade Regional Integrada do Alto Uruguai e das Missões (URI). Mestre em Engenharia de Produção pela UFSM. Doutorando em Engenharia de Produção pela Universidade Federal do Rio Grande do Sul (UFRGS) 